Cad.Est.Ling., Campinas, (44):133-141, Jan./Jun. 2003

\title{
ARTIGO INDEFINIDO E ANÁFORA ${ }^{1}$
}

\author{
MARIA LUIZA CUNHA LIMA ${ }^{2}$ \\ (UNICAMP)
}

\begin{abstract}
In this paper we begin to analyze ocurrences of anaphoric indefinite expressions. In recent semantic and linguistic theory indefinites are not expected, only recently the phenomenon has been recognized by some theorists. We examine critically some classifications already proposed and try to point out new perspectives to future investigations.
\end{abstract}

\section{INTRODUÇÃO}

Nesse trabalho investigamos casos de anáforas realizadas por sintagmas nominais indefinidos. Ao contrário do que normalmente se previu, anáforas podem ser introduzidas por artigos indefinidos, com funções bem diversificadas. As classificações propostas até o momento, como a Swcharz (2000), parecem confusas e incompletas, deixando de lado ocorrências importantes do fenômeno.

Nossa proposta aqui é apenas apontar casos não previstos pela classificação de Swcharz (reafirmando a existência desse tipo de anáfora) e tecer considerações algumas considerações sobre as implicações teóricas que o reconhecimento da anáfora realizada por $\mathrm{SN}$ indefinido teriam para a teoria da referenciação.

\section{O USO ANAFÓRICO DO ARTIGO INDEFINIDO}

A anáfora introduzida por artigo indefinido é um tema pouco debatido em geral na literatura sobre o processo anafórico. A maioria dos autores, (como Apothéloz, 1995 e Kleiber, 2001), ao considerarem o fenômeno anafórico, privilegiam retomadas através do uso do artigo definido e de pronomes demonstrativos e possessivos.

${ }^{1}$ Agradecemos os exemplos gentilmente cedidos por Ingedore Koch, Mônica Cavalcante e sobretudo a Rodolfo Ilari por permitir o uso de exemplos extraídos do CAIMBRA (Corpus de Anáfora da Imprensa Brasileira) montado por ele.

2 A autora é doutoranda do Programa de Doutorado em Lingüística da Universidade Estadual de Campinas, desenvolvendo tese sob a orientação da Prof ${ }^{a}$ Dra. Ingedore G.V. Koch e co-orientação do Prof. Dr. Edson Françozo. 
Essa atitude deve-se, em parte, à compreensão clássica de que, em princípio, o artigo indefinido serve para introduzir um elemento novo no discurso e não para retomá-lo. Vários autores aceitam essa função apenas introdutória do indefinido como não problemática. Veja-se, por exemplo, a interpretação que Fauconnier (1994:20) propõe para o uso do indefinido:

The noun phrase $\mathbf{a} \mathbf{N}$ in a linguistic expression sets up a new element $\mathbf{w}$ in some space (...) In contrast to indefinite descriptions that set up new elements, the direct function of definite descriptions is to point out elements already there.

Para Fauconnier (1994), seguindo a compreensão geral sobre o tema, o artigo indefinido sempre cria um elemento novo ${ }^{3}$ nos espaços mentais construídos por um determinado texto. O definido é uma indicação de que o elemento determinado por ele já existe em um destes espaços e precisa apenas ser localizado e reativado.

Mesmo seguindo outra linha de análise, Kleiber (2001:17) também afirma, a respeito da anáfora associativa (mas numa argumentação que se pode estender às ocorrências anafóricas em geral) que:

a restrição a respeito do caráter conhecido do referente novo introduzido tem por efeito excluir as expressões com determinante indefinido porque nós reconhecemos geralmente que os SN indefinidos têm a virtude de introduzir um novo referente não conhecido do interlocutor (...) Um sintagma nominal indefinido, como é bem conhecido, geralmente não é tido como podendo ser anafórico.

Apenas recentemente, o papel dos indefinidos para a realização de anáforas tem chamado a atenção de diversos pesquisadores, como Schwarz (2000), Koch (2002a; 2002b) e Cavalcante (2003). Essas autoras são unânimes em afirmar que ao contrário do que se previu inicialmente, o indefinido também funciona como introdutor de expressões nominais anafóricas e também serve à continuidade referencial, como é possível confirmar a partir dos exemplos seguintes, o primeiro extraído de um texto escrito e o segundo de um texto de falado:

\section{Exemplo 1}

Aconteceu com um amigo meu, fictício, claro. Ele estava voltando para casa como fazia, com fidelidade rotineira, todos os dias à mesma hora. Um homem dos seus 40 anos, naquela idade em que já sabe que nunca será dono de cassino em Samarkand, com diamantes nos dentes, mas ainda pode esperar alguma coisa na vida, como ganhar na loteria ou furar-lhe um pneu. Furoulhe um pneu. (Luiz Fernando Veríssimo, A aliança)

\section{Exemplo 2}

C a gente tinha assistido TODOS todos os filmes ...então a gente falô assim: ... vamos fazê um negócio diferente então né? ... ((fala rápida)) vamo fazê um negócio diferente/ então:: pegá

${ }^{3}$ É importante frisar que criar um elemento num espaço mental, no modelo proposto por Fauconnier (1994), equivale a introduzir um novo referente. 
um:: ... striptize ... eu falei brincando/ o S falô tá legal

e aqui tem um ... pronto! (Exemplo extraído do corpus do Nelfe ${ }^{4}$ )

Nos exemplos acima, parece claro que se tratam de retomadas anafóricas, ambas casos de anáforas diretas que recategorizam amigo meu e negócio diferente, respectivamente.

Se parece claro, a partir dos exemplos, que os $\mathrm{SN}$ indefinidos podem ser anafóricos, ainda assim, ao falarmos de anáfora introduzida por artigo indefinido a primeira dificuldade é reconhecer se se trata mesmo de anáfora. Em outras palavras, qual é o critério que define que uma ocorrência é efetivamente anafórica, quais os motivos que justificam falar em anáfora?

\title{
Exemplo 3
}

Bush, segundo declarou, pretende usar a invasão do país para instalar ali um regime democrático que sirva de inspiração de liberdade para outras nações da região. Sem contar o fato de que é fácil para os EUA ganhar uma guerra contra os iraquianos mas é difícil mudar o regime e manter em seu lugar um governo democrático estável, há o risco de produzir mais instabilidade ainda no Oriente Médio

Nesse caso, é difícil determinar se existe continuidade referencial entre as duas ocorrências, isto é, um regime democrático é de alguma maneira retomado por um governo democrático ou se as ocorrências são autônomas. Os critérios clássicos para apontar que está havendo uma retomada ou remissão não se aplicam aqui, já que a retomada seria normalmente prevista com o uso do definido. Observe-se também o exemplo seguinte:

\begin{abstract}
Exemplo 4
A repressão policial na cracolândia, reduto de traficantes e dependentes de crack no centro de São Paulo divide opiniões. De um lado, especialistas no tratamento de dependentes condenam a estratégia do governo para expulsar os viciados da região. De outro, comerciantes locais aplaudem a iniciativa. Para o psiquiatra Auro Lescher, coordenador do Projeto Quixote, criado pela Escola Paulista de Medicina para atender crianças e adolescentes que vivem nas ruas, a ação da polícia é apenas uma maneira 'de varrer a sujeira para debaixo do tapete'. / Estão tratando uma questão social como se fosse uma questão urbanística e financeira. Enquanto adotarem medidas repressivas estarão perpetuando um grave problema. (FSP 03/09/2000 Exemplo extraído do CAIMBRA)
\end{abstract}

Koch (2002b: 4) transcreve a seguinte reflexão de Ilari a respeito desse exemplo: que grave problema é anafórico, é apenas uma intuição. Aparentemente, nada muda se um for substituído por esse; por outro lado, um grave problema poderia ser retomado, em frases seguintes por 'o problema', 'problema' etc., mas não estará introduzindo um referente novo. Seriam esses dois motivos suficientes para que possamos falar de anáfora?"

O fato do indefinido poder ser substituído por um definido ou pronome demonstrativo parece não ser fundamental para caracterizar a anáfora, existem casos

\footnotetext{
${ }^{4}$ Núcleo de Estudos de Língua Falada e Escrita, da UFPE.
} 
claramente anafóricos em que essa mudança é possível, embora com uma ligeira mudança de sentido (exemplo 5), enquanto em outros casos o determinante indefinido do SN anafórico não poderia ser subsitituído por um definido, como no exemplo 6:

\begin{abstract}
Exemplo 5
Rainha da autopromoção, às vésperas de lançar um novo disco, Madonna, 44 anos, caprichou na pose para a revista W. Queria algo diferente e, com certeza, conseguiu. "Com tudo o que está acontecendo no mundo, acho que nos preocupamos demais com as coisas erradas", filosofou. A impressionante seqüência de contorcionismos, resultado de duas décadas de ioga e dança, pretende refletir 'a paisagem interna de uma artista performática'.
\end{abstract}

\title{
Exemplo 6
}

Uma catástrofe ameaça uma das últimas colônias de gorilas da África. Uma epidemia de Ebola já matou mais de 300 desses grandes macacos no santuário de Lossi, no noroeste do Congo. Trata-se de uma perda devastadora, pois representa o desaparecimento de um quarto da população de gorilas da reserva.

Em 5, poder-se-ia dizer que o uso das expressões da artista performática, ou dessa artista performática no lugar de uma artista performática, embora enfraqueça a capacidade de fazer referência a uma característica que artistas performáticos teriam em geral, não prejudicaria a capacidade de identificar Madonna como o referente e de estabelecer uma interpretação coerente para o texto não estaria prejudicada.

Já em 6, a segunda sentença não poderia começar com A epidemia de Ebola, uma vez que a informação contida no antecedente não parece ser suficiente para permitir o seu emprego. Note-se que a primeira sentença é completamente dispensável para a interpretação da segunda, isto é, se o texto começasse com Uma epidemia de Ebola já matou...o sentido estaria preservado. No entanto, parece indiscutível que Uma epidemia retoma Uma catástrofe, especificando-a.

Para obtermos um critério decisivo, então, parece indispensável voltarmos à definição de anáfora adotada e confrontá-la com nossos dados.

\section{DEFINIÇÕES DE ANÁFORA}

$\mathrm{Na}$ literatura existe uma grande divergência a respeito dos critérios de definição do fenômeno da anáfora, divergências que formam, grosso modo, dois blocos distintos: um que corresponde a concepções mais estreitas do fenômeno, que inclui autores como Kleiber (2001) ou Halliday (1985); e outro bloco que compartilha concepções mais amplas (Apothéloz,1994, Berrendonner,1995, Marcuschi e Koch, 2002).

Os partidários da concepção mais estreita de anáfora a vêem como um fenômeno fundamentalmente ligado à coesão textual e caracterizado pela retomada de um segmento de texto por outro, nesse sentido, o anafórico "refere-se ao seu antecedente". Para essa concepção, portanto, a anáfora deve ser correferencial e o antecedente deve ser explícito. Uma característica adicional do anafórico, quando este é um grupo nominal, é que, para estes autores, ele deve ser introduzido por um determinante 
definido,além disso, que exista alguma relação semântica-lexical ou léxicoestereotípica, ( por exemplo, uma relação meronínica ou de ingrediência), entre os nomes núcleo do anafórico e seu antecedente.

Já a concepção ampliada foca-se mais na dinâmica textual e na construção de objetos de discurso (Apothéloz, 1994; Berrendonner, 1995; Mondada e Dubois 1995; Marcuschi e Koch, 2002). Para os partidários dessa concepção, que também é adotada aqui, as anáforas servem tanto à continuidade e manutenção referenciais quanto à construção dos sentidos no texto, sendo fundamentais para o processo de referenciação. Como os aspectos centrais da análise estão relacionados a essa dinâmica, o traço fundamental da anáfora é a retomada ou a remissão a elementos anteriores do co-texto que alguns elementos textuais (notadamente pronomes e grupos nominais) demandam para o cálculo do seu sentido.

Seguindo essa concepção, portanto, para caracterizar a anáfora o fundamental é a continuidade referencial, ou melhor dizendo, que referentes anteriormente ativados participem do cálculo do sentido de novas expressões introduzidas.

No caso do indefinido, então, parece ser fundamental para caracterizar a existência ou não de anáfora um refinamento da concepção de continuidade referencial que certamente põe em jogo a relação entre o nome núcleo de uma expressão nome e seu antecedente, mais do que a regras gramaticais de emprego dos determinantes definido e indefinido. O passo seguinte para a explicação dos sintagmas nominais indefinidos anafóricos é procurar observar os casos em que sistematicamente seu emprego é possível e ou preferido.

Somos incapazes de, no espaço disponível tentar realizar essa tarefa. No entanto, é possível resenhar propostas anteriores e apontar alguns caminhos que podem iluminar a solução do problema.

\section{CASOS DE EMPREGO SN INDEFINIDO ANAFÓRICO}

Para Schwarz (2000), são três as razões que licenciam a ocorrência de um sintagma nominal indefinido anafórico:

1) Quando a expressão tem valor partitivo, isto é, quando o elemento anafórico é membro de um grupo, ou parte de um referente já mencionado, como no exemplo 7:

A compradora mais freqüente da Daslu é aquela mulher que vai à loja para conhecer o ponto e acaba fazendo umas comprinhas. A conta fica mais interessante quando se trata do grupo das 100 clientes vip da casa. De acordo com os últimos números, uma vip gasta 40000 reais por mês na Daslu para manter o guarda-roupa atualizado (Veja 26/03/03).

2) Quando a vagueza própria do indefinido é utilizada para criar um efeito de suspense:

Exemplo 8

O detetive fotografou o homem entrando em motel com sua amante. No dia seguinte, mais um casamento se desfazia. 
3) quando a informação nova normalmente presente numa anáfora com recategorização é mais fortemente focalizada que a seqüencialidade da cadeia coesiva:

\begin{abstract}
Exemplo 9
Todas as evidências indicam que o assassinato do juiz-corregedor José Machado Dias se deu a mando do crime organizado. Se o que parece óbvio se confirmar, será um precedente gravíssimo para o Brasil, que terá perdido uma batalha na guerra contra as quadrilhas. Mais do que um bárbaro homicídio, o que houve foi um atentado contra o poder público e o Estado de Direito.
\end{abstract}

É importante frisar que a classificação proposta por Swcharz é uma das primeiras disponíveis para o fenômeno e que vale mais como um levantamento do que como um estudo profundo (o objetivo da autora não era explicar o uso do definido versus indefinido, mas investigar as ocorrências de anáforas indiretas).

Vemos dois problemas nessa classificação. Em primeiro lugar, os critérios que, segundo ela, permitem o uso do indefinido são inconsistentes entre si, envolvendo ora critérios estilísticos, ora semânticos, ora relacionados ao processamento cognitivo. O caso 1 é caracterizado em termos da semântica do artigo indefinido, enquanto no caso 2 o critério fundamental é estilístico, e o caso 3 tem a ver com o processamento cognitivo da informação num sentido mais amplo.

O segundo problema é que uma classificação como essa não nos diz em que casos o indefinido pode ou não ser utilizado, em que casos o uso é opcional e quais as razões decisivas na escolha de um ou de outro nos casos opcionais. Enfim, a classificação é vaga e carece de coerência interna em seus critérios.

Os casos 1 e 3 apontados por Swcharz (2000) merecem um exame um pouco mais cuidadoso, como veremos adiante, já o caso 2 vai ser deixado de lado aqui, pois, apesar dos aspectos estilísticos serem obviamente importantes para as escolhas lexicais, nos parece no momento que o fenômeno tem que ser explicado melhor de um ponto de vista textual e de processamento cognitivo.

Além da incoerência interna da classificação, o segundo problema é que, como aponta Koch (2002b), existem ocorrências que não caem em nenhum dos três tipos propostos, como nos exemplos abaixo:

\title{
Exemplo 10
}

Deus que não tinha problema de verba, nem uma oposição para ficar dizendo "Projetos faraônicos! Projetos faraônicos!", resolveu, numa semana que não tinha mais nada para fazer, criar o mundo. E criou o céu e a terra e as estrelas, e viu que eram razoáveis. Mas achou que faltava vida na sua criação e - sem uma idéia muito firme do que queria - começou a experimentar com formas vivas. Fez amebas, insetos, répteis. As baratas, as formigas etc. Mas, apesar de algumas coisas bem resolvidas - a borboleta, por exemplo -, nada realmente o agradou. Decidiu que estava se reprimindo e partiu para grandes projetos: o mamute, o dinossauro e, numa fase especialmente megalomaníaca, a baleia. Mas ainda não era bem aquilo. E então bolou um bípede. Uma variação do macaco, sem tanto cabelo. (Luiz Fernando Veríssimo, Homens) 


\section{Exemplo 11}

E sabe de outra coisa? Eu não precisava ficar na cidade durante o carnaval. Foi tudo mentira. Eu não tinha trabalho acumulado no escritório coisíssima nenhuma. Eu fiquei sabe pra quê? Pra testar você. Ficar na cidade foi como dar um salto mortal, sem rede, só para você se você me pegaria no ar. Um teste do nosso amor.

Esses exemplos não são casos de uso partitivo, nem tampouco criam suspense e é difícil decidir se o mais importante é informação nova ou a cadeia coesiva, principalmente num caso de encapsulamento anafórico com rotulação como acontece em 11.

Voltemos por hora aos casos 1 e 2 propostos por Schwarz. O uso partitivo parece mesmo ser responsável por grande parte dos empregos anafóricos do SN indefinido, no entanto para alguns autores, a indefinitude do SN é apenas aparente. Para Kleiber(2001), por exemplo, o que é retomado é o conjunto (pressuposto ou já construído) do qual o elemento novo introduzido faz parte e sobre esse conjunto é feita uma operação de extração de uma sub-parte. Para o autor, esse uso partitivo não contorna a exigência de definitude para o anafórico porque o conjunto do qual uma parte é tomada é definido, e esse aspecto definido do conjunto, segundo ele, é indispensável para que a anáfora opere com o indefinido.

Usos existenciais e, simultaneamente anafóricos, do indefinido são considerados impossíveis por Kleiber. No entanto, parece inegável que o exemplo abaixo, que opera uma recategorização do referente, é existencial, ao mesmo que anafórico (assim como outros do mesmo tipo):

\section{Exemplo 12}

Alguns hotéis brasileiros imitam os americanos e deixam uma Bíblia no quarto, e ela tem sido minha salvação, embora não no modo pretendido. Nada como um best-seller numa hora dessas.

Se deixarmos de lado o uso partitivo do artigo e nos voltarmos para seus usos existenciais perceberemos que o 3 caso da classificação de Schwarz é também um caso existencial, embora existam outros que não se adequam à descrição proposta pela autora.

$\mathrm{O}$ artigo definido funciona como uma instrução para a busca de algum elemento anterior que sirva de ancoragem para o segmento introduzido por tal artigo. O artigo aí privilegia a informação de que existe uma continuidade referencial, ou seja, dá mais informações sobre a seqüencialidade e a coesão da cadeia referencial.

Um uso do indefinido parece dar mais destaque para o aspecto novo contido na recategorização ou na paráfrase, ou seja o aspecto novo da informação é posto em relevo, como nos exemplos 1 e 12. A paráfrase também parece favorecer acima de tudo o aspecto de novidade, o nome núcleo é reativado e novas predicações são aplicadas sobre ele. Vejam-se os exemplos abaixo, em que a paráfrase apenas expande as informações sobre feijoada ficando no limite da repetição: 


\section{Exemplo 13}

C é: ... foi o dia que a gente foi comê uma feijoada no well's

M ah é:?

C é: quase que agente deixa todo nosso dinheiro lá ((risadas))

cem paus uma feijoada lá

cem cruzeiros uma [feijoada prá dois

\section{Exemplo 14}

Se a cena pudesse ser confiada a um profissional de comunicação, seria diferente. $\mathrm{O}$ mal do mundo é que as piores notícias quase sempre nos são dadas por amadores. Se sua imagem no espelho fosse confiada a um profissional de marquetchim (sic), em vez da sua cara no espelho revelador você veria a Isadora Ribeiro (Luiz Fernando Veríssimo, Espelho).

Se essa explicação se revelar aceitável, ficará claro que embora a contribuição do artigo para atribuição do status de dado ou novo em um texto seja evidentemente muito importante (como já têm provado numerosos estudos, veja-se Prince, 1992; entre outros), a relação entre o nome núcleo do anafórico e os antecedentes é também muito importante. As informações semânticas contidas nos itens lexicais são essenciais na identificação do antecedente. Voltemos ao exemplo 6:

Uma catástrofe ameaça uma das últimas colônias de gorilas da África. Uma epidemia de Ebola já matou mais de 300 desses grandes macacos no santuário de Lossi, no noroeste do Congo.

A palavra catástrofe, embora certamente retomada por epidemia na sentença seguinte, não licencia o uso do definido para a anáfora, como se viu, não é possível substituir Uma epidemia por A epidemia nem por Essa epidemia. Aparentemente, isso se deve ao fato de que a catástrofe, um termo genérico ou hiperônimo não fornece informações suficientes para que epidemia seja processada como algo dado. Nesse caso temos uma anáfora especificadora, um movimento quase catafórico que recategoriza o antecedente.

A investigação do papel do léxico parece, portanto, fundamental para a compreensão dos anafóricos com indefinido, como de resto para os fenômenos anafóricos em geral. O proveitoso, no caso, parece ser a conjunção entre o status informacional aportado pelo artigo (que dá instruções como: trate isso como dado, trate isso como novo) com as informações tornadas disponíveis pelos núcleos, sinalizando quão automática pode ser (ou o produtor espera que seja) a inferência que liga uma anáfora a seus antecedentes.

\section{CONSIDERAÇÕES FINAIS}

O uso anafórico do artigo indefinido está longe de ser propriamente investigado, tanto em português como em outras línguas. Vários fatores parecem entrar em jogo para explicar e justificar esse uso. Apontamos aqui alguns elementos que merecem investigação aprofundada para o esclarecimento do tema, sobretudo a busca de um conceito de anáfora que incorpore essas ocorrências e o papel do léxico em possibilitar 
ou não o uso do indefinido. Muitos assuntos foram deixados de fora, por falta de espaço, como o papel das atividades predicativas nesse licenciamento assim como reflexões sobre a relação entre uso indefinido e aposto.

Todos esses aspectos merecem investigação detalhada, que poderá lançar luz, esperamos, sobre a dinâmica da construção e manutenção dos referentes no texto.

\section{BIBLIOGRAFIA}

APOTHÉLOZ, Denis (1995). Rôle et Fonctionnement de l'anaphore dans la dynamique textuelle. Genebra: Droz.

BERRENDONNNER, A. \& REICHLER-BÉGUELIN, M-J. (eds). (1995). Du syntagme nominal aux objetsde-discours. SN complexes, nominalisation, anaphors. Neuchâtel: Institut de Linguistique de l'Université de Neuchâtel.

CAVALCANTE, Mônica. (2003). Entre o definido e o indefinido. Conferência apresentada por ocasião do III Congresso Internacional da ABRALIN no Rio de Janeiro.

FAUCONNIER, Gilles. (1994). Mental Spaces: Aspects of meaning construction in natural language. Cambridge (MA): Cambridge University Press.

HALLIDAY, M. (1985). Introduction to Functional Grammar. Londres: Edward Arnold.

KLEIBER, Georges (2001). L'anaphore associative. Paris: Press Universitaire Française.

KOCH, Ingedore (2002a) Desvendando os segredos do texto. São Paulo: Cortez. (2002b). Expressões nominais indefinidas e a progressão referencial. Campinas: mimeo.

KOCH, I.V. \& MARCUSCHI, L.A (2002). Progressão Referencial na Língua Falada. Gramática do Português Falado. Vol. VIII. Campinas: Editora da Unicamp.

MONDADA, L. \& DUBOIS, D. (1995) Construction des objets de discours et categorisation: une approche des processus de référentiation. In: BERRENDONNNER, A. \& REICHLER-BÉGUELIN, M-J. (eds). (1995). Du syntagme nominal aux objets-de-discours. SN complexes, nominalisation, anaphores Neuchâtel: Institut de Linguistique de l'Université de Neuchâtel. p. 273-302.

PRINCE, Ellen. (1992) The ZPG Letter: subjects, definiteness, and information status. In: MANN, W. C. \& THOMPSON, S. A. (eds). Discourse description: diverse linguistic analyses of a fund-raising text. Amsterdam: John Benjamins: 295-325.

SWCHARZ, Monika. (2000). Indirekte Anaphern in Texten. Tübingen: Niemeyer. 